\title{
INJECTION-DIGEST METHOD FOR STUDYING RETINAL VESSELS*
}

\author{
BY \\ G. E. KNIGHT \\ Department of Pathology, Institute of Ophthalmology, University of London
}

IN the study of the retinal circulation numerous techniques have been employed, all of which have their advantages and disadvantages. Flat preparations alone (Ballantyne and Loewenstein, 1944) reveal very little detail; benzidine-staining (Ashton, 1949; Michaelson, 1954) fails unless the vessels are engorged; the periodic acidSchiff technique (Friedenwald, 1949; Ashton, 1949), especially in pathological specimens, provides insufficient contrast between retina and vessels; intravascular injections with Indian ink (Ashton, 1950), latex solutions (Ashton, 1950; Janes, 1959), or silver nitrate solutions (Hausler and Sibay, 1959), while demonstrating the morphology of the vessels better than any previous method, obscure cellular detail in the vessel wall. The most recent digest techniques with trypsin (Kuwabara and Cogan, 1960), or pepsin and trypsin (Ashton, 1963), although providing a perfect demonstration of cellular details, do not show their relation to closure of the capillaries or to pathology in the surrounding retinal tissue, which is sacrificed in the process.

Clearly, a technique which would combine the advantages of injection with those of digestion would be of value. For this purpose it is essential to obtain an injection mass which provides a picture as satisfactory as that obtained with Indian ink, does not leak through the vessel walls, does not interfere with the subsequent digestion and staining, and which may later be decolorized so that cellular detail is not obscured. Soluble Berlin blue was found to satisfy all these requirements.

\section{Method}

The injection may be made directly into the central vessels in human eyes enucleated at post mortem or operation, or in experimental animals by cardiac perfusion.

(1) Irrigate vessels with $\mathbf{0 \cdot 2}$ per cent. aqueous solution of sodium nitrite until free of blood.

(2) Inject with 5 per cent. aqueous solution of Soluble Berlin blue (in the case of cardiac perfusion until the tongue and the skin of the face are a deep blue).

(3) Fix in 10 per cent. formol saline for 24 hours.

(4) Open eye by cutting through the ora serrata and float out the retina (Fig. 1).

(5) Digest retina, or segment, by either the trypsin or the pepsin-trypsin technique.

* Received for publication May 11, 1965. 


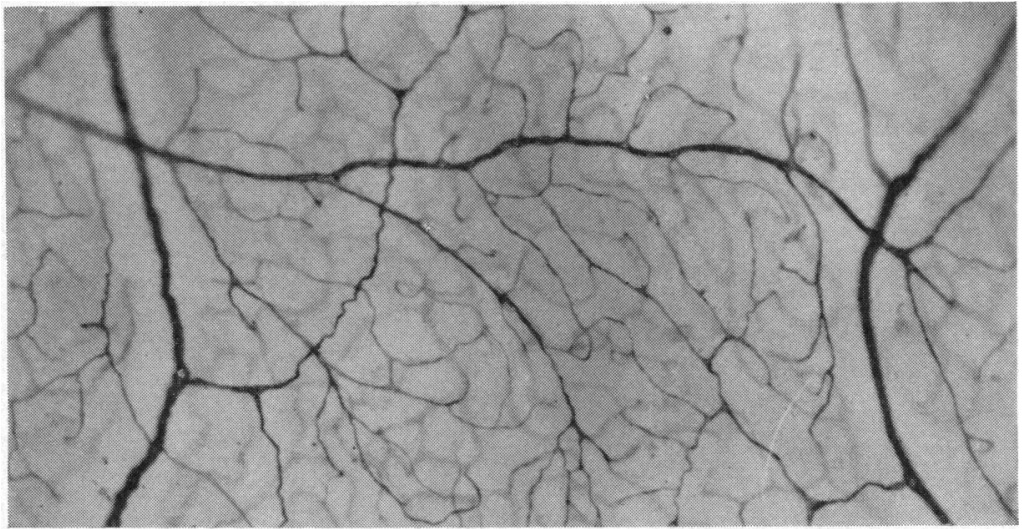

FIG. 1.-Cat retina injected with Berlin blue, showing detailed anatomy of fine capillaries. Flat preparation. $\times 68$.

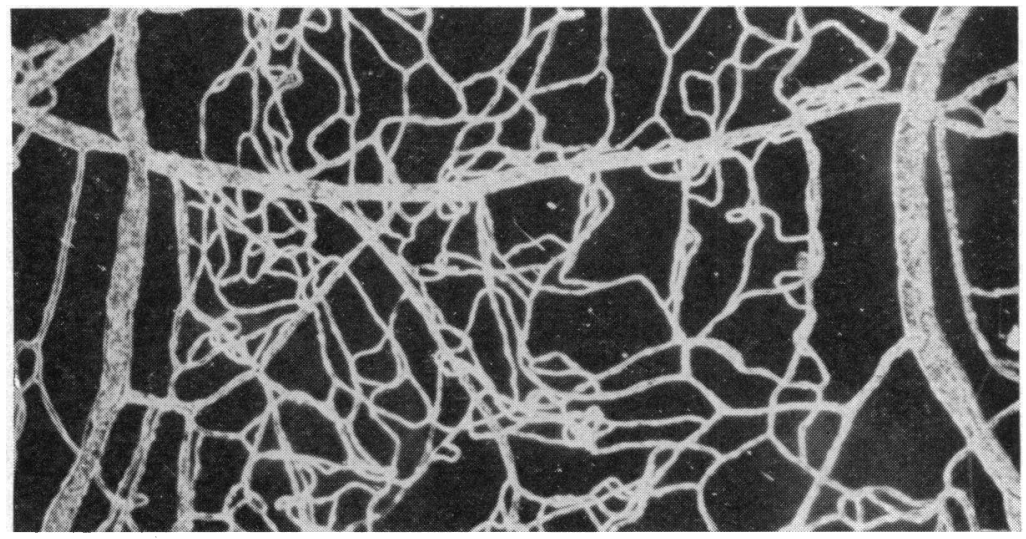

FIG. 2.-Same area as shown in Fig. 1, after digestion in pepsin-trypsin. Note some distortion of normal anatomical relationship of capillaries. Dark-ground illumination. $\times 68$.

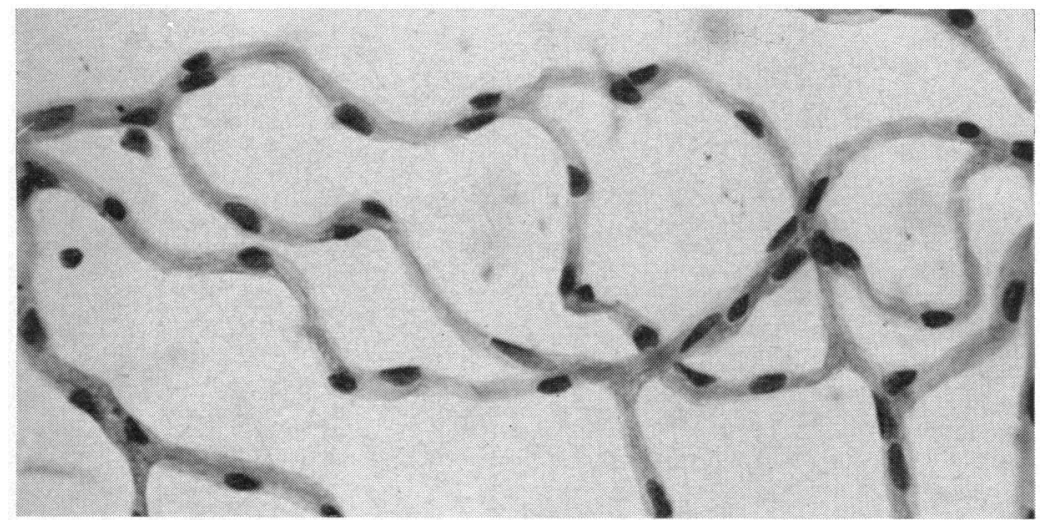

FIG. 3.- High-power view of cat retina showing cellular detail, following digestion and decolorization of the injected specimen. PAS and haematoxylin. $\times 440$. 
(6) Float digested vessels on to slide and allow to dry (Fig. 2).

(7) Decolorize with either 1 per cent. sodium carbonate solution for 24 hours or with a 5 per cent. solution for 2 to 3 hours.

(8) Stain with either haematoxylin and eosin or PAS and haematoxylin (Fig. 3).

Note.-The digested specimen may be stained without decolorizing, but although the nuclear detail is visible within the injected vessels, some of the blue may be lost during the process of digestion.

I would like to thank Prof. N. Ashton for his encouragement in the investigation of this technique.

Ashton, N. (1949). Brit. J. Ophthal., 33, 407.

\section{REFERENCES} (1950). Ibid., 34, 38. (1963). Ibid., 47, 521.

Ballantyne, A. J., and Loewenstein, A. (1944). Ibid., 28, 593.

Friedenwald, J. S. (1949). Amer. J. Ophthal., 32, 487.

Hausler, H. R., and Sibay, T. M. (1959). Ibid., 48, no. 1, pt. 2, p. 138.

Janes, R. G. (1959). A.M.A. Arch. Path., 67, 386.

Kuwabara, T., and Cogan, D. G. (1960). Arch. Ophthal. (Chicago), 64, 904.

Michaelson, I. C. (1954). "Retinal Circulation in Man and Animals". Thomas, Springfield, Ill. 